\title{
Trapping of the malaria vector Anopheles gambiae with odour-baited MM-X traps in semi-field conditions in western Kenya Basilio N Njiru' ${ }^{1}$, Wolfgang R Mukabana ${ }^{2}$, Willem Takken ${ }^{4}$ and Bart GJ Knols*3,4
} \author{
Box 8031, $6700 \mathrm{EH}$ Wageningen, The Netherlands \\ Email: Basilio N Njiru - bnjiru@mbita.mimcom.net; Wolfgang R Mukabana - rmukabana@uonbi.ac.ke; \\ Willem Takken - willem.takken@wur.nl; Bart GJ Knols* - b.knols@iaea.org \\ * Corresponding author
}

Address: ${ }^{1}$ International Centre of Insect Physiology and Ecology (ICIPE), Thomas Odhiambo Campus at Mbita Point, P.O. Box 30, Mbita, Kenya, ${ }^{2}$ Department of Zoology, University of Nairobi, P.O. Box 30197 - 00100 GPO, Nairobi, Kenya, 3International Atomic Energy Agency (IAEA), Agency's Laboratories Seibersdorf, A2444 Seibersdorf, Austria and ${ }^{4}$ Laboratory of Entomology, Wageningen University and Research Center, P.O.

Published: 15 May 2006

Malaria Journal 2006, 5:39 doi:10.1 186/1475-2875-5-39

This article is available from: http://www.malariajournal.com/content/5/I/39

(C) 2006 Njiru et al; licensee BioMed Central Ltd.

This is an Open Access article distributed under the terms of the Creative Commons Attribution License (http://creativecommons.org/licenses/by/2.0), which permits unrestricted use, distribution, and reproduction in any medium, provided the original work is properly cited.
Received: 25 January 2006

Accepted: 15 May 2006

\begin{abstract}
Background: The successful development of odour-baited trapping systems for mosquitoes depends on the identification of behaviourally active semiochemicals, besides the design and operating principles of such devices. A large variety of 'attractants' has been identified in laboratory investigations, yet few of these increase trap catches in the field. A contained system, intermediate between the laboratory and open field, is presented and previous reports that human foot odour induces behavioural responses of Anopheles gambiae confirmed.
\end{abstract}

Methods: The response of 3-5 day old female An. gambiae towards odour-baited counterflow geometry traps (MM-X model; American Biophysics Corp., RI) was studied in semi-field (screen house) conditions in western Kenya. Traps were baited with human foot odour (collected on socks), carbon dioxide $\left(\mathrm{CO}_{2}, 500 \mathrm{ml} \mathrm{min}-1\right)$, ammonia $\left(\mathrm{NH}_{3}\right)$, I-octen-3-ol, or various combinations thereof. Trap catches were log $(x+1)$ transformed and subjected to Latin square analysis of variance procedures.

Results: Apart from I-octen-3-ol, all odour baits caused significant $(P<0.05)$ increases in trap catches over non-baited traps. Foot odour remained behaviourally active for at least 8 days after collection on nylon or cotton sock fabric. A synergistic response $(P<0.001)$ was observed towards the combination of foot odour and $\mathrm{CO}_{2}$, which increased catches of these odours alone by 3.8 and 2.7 times, respectively.

Conclusion: These results are the first to report behavioural responses of an African malaria vector to human foot odour outside the laboratory, and further investigation of fractions and/or individual chemical components of this odour complex are called for. Semi-field systems offer the prospect of high-throughput screening of candidate kairomones, which may expedite the development of efficient trap-bait systems for this and other African mosquito species. 


\section{Background}

Development of odour-baited trapping devices for biting insects remains a challenge for many important species, including African malaria vectors $[1,2]$. Such traps may find application in mosquito surveillance [3], risk assessment and forecasting [4], and/or be used en masse for population suppression and disease transmission reduction similar to trap-bait systems developed for tsetse flies [5-7]. There are three important components of trap development, namely the 'attractant', the physical trap design, and trapping mechanism used. A fourth set of essentials follows, namely the cost, applicability and acceptance of such devices by end-users in anticipated market sectors.

Anopheles gambiae s.s. is a highly anthropophilic mosquito, with a tendency to blood feed and rest inside houses [8]. Studies on semiochemicals affecting its hostseeking behaviour have intensified since the late 1980s [1], with the main aim to replace the Human Biting Catch (HBC). Some traps use whole human odour, like the CDC light trap placed next to an occupied bednet [9], the OBET $[10,11]$ and Mbita traps [12-14]. However, humans vary substantially in their innate attractiveness towards An. gambiae s.s. $[15,16]$, which has been attributed to the presence of allomonal effects of breath [17], variability in skin microfloral composition $[18,19]$, or both. Identification of specific kairomones with key involvement in governing the host-seeking process has therefore been advocated [20].

Of the several hundreds of volatiles produced by humans $[21,22]$, a fair number have been reported to elicit behavioural responses by An. gambiae s.s. These comprise commonly known kairomones like carbon dioxide [23-25], but also carboxylic fatty acids [26,27], oxo-carboxylic acids [28], ketones [29], phenols [29,30], L-lactic acid [31], and ammonia [32].

It remains speculative why attempts to reproduce laboratory studies under field conditions have been unsuccessful to date, although the substantial differences between olfactometer-based studies [26-31] and field-based trapping methods may be a prime cause for this. Alternatively, prolonged maintenance of mosquito strains under artificial laboratory conditions may result in distorted behaviour and responses to 'attractants' that would not be similar in nature. A third reason relates to the highly endophagic behaviour of An. gambiae s.s. that results in strong 'competition' between odour-baited traps and human hosts present in the indoor environment, arguably always in favour of humans expressing the full range of physical and chemical cues. Finally, and in contrast with laboratory studies, ambient climatic conditions may vary over space and time, and cause highly variable trap catches in the field.
The development and commercialization of traps based on counterflow geometry technology in the late 1990s by the American Biophysics Corporation has resulted in efficacy evaluation studies for a range of mosquito species in various geographical settings, including Africa [33-35]. Many of these evaluations inferred superiority of this technology over conventional traps such as the CDC light trap [36], which supports the view that trap design rather than the stimuli used affect the trapping efficiency.

In the present study, it was aimed to reproduce some previous laboratory findings under semi-natural conditions in western Kenya. In large outdoor cages (for a description see [37]) experimental counterflow geometry traps were deployed (see below), baited with human foot odour, $\mathrm{CO}_{2}, \mathrm{NH}_{3}$, 1-octen-3-ol, or various combinations thereof, as a first step to develop more appropriate research tools for anticipated open field studies.

\section{Materials and methods Mosquitoes}

Two strains of An. gambiae s.s. mosquitoes were used. These originated either from Njage village, $70 \mathrm{~km}$ from Ifakara, South-East Tanzania, (maintained under laboratory conditions since April 1996) or from Mbita Point, Western Kenya (maintained since January 2001). Adult mosquitoes belonging to these strains were kept in $30 \times$ $30 \times 30 \mathrm{~cm}$ gauze-covered cages under ambient conditions at the Thomas Odhiambo Campus $\left(00^{\circ} 25^{\prime} \mathrm{S}, 34^{\circ} 13^{\prime} \mathrm{E}\right)$, Nyanza Province, western Kenya, a field station of the International Centre for Insect Physiology and Ecology (ICIPE). They were maintained on a $6 \%$ glucose solution and provided with water on cotton wicks to increase relative humidity in cages. Mosquitoes were fed on a human arm for 10 min every three days. Eggs, laid on moist filter paper, were transferred into breeding trays and larvae developed up to pupal stage in water originating from Lake Victoria. Water was replaced at 1-2 day intervals. Larvae were fed 2-3 times daily on Tetramin ${ }^{\circledR}$ fish food. Pupae were collected daily and transferred to adult holding cages containing sugar water and water-moistened cotton wicks. Further details on mosquito colony maintenance are reported elsewhere [37].

The age of females used in the experiments was 3-5 days and these were starved for 6 hrs before the experiments in a $1 \mathrm{~L}$ cup, covered by mosquito netting, and were offered water-moistened wicks only.

\section{Experimental procedures}

All experiments were conducted in a greenhouse (Cambridge Glass House Co. Ltd., UK) with a glass-panelled roof and gauze covered side walls. Inside, a layer of sand was put on the floor and a large mosquito-netting cage $(10 \times 6 \times 2.5 \mathrm{~m}$; mesh width $3 \mathrm{~mm})$ was mounted. Two 
counter flow geometry traps (MM-X model; American Biophysics Corp., USA; Fig 1.)), were suspended $8 \mathrm{~m}$ from each other, with the odour outlet $15 \mathrm{~cm}$ above ground level. For a detailed description of the trap see [38]. Every test night, 200 experimental mosquitoes were released from the centre of the greenhouse at $19.00 \mathrm{hrs}$ local time and trap catches collected at 07.00 hrs the following morning. Trap positions and treatments were randomised over experimental nights to avoid possible side effects.

\section{Experiments with foot odour}

Foot odours were either collected from BNN (male African, age 34 yrs) or BGJK (male Caucasian, 35 yrs) on sock material by wearing them for $12 \mathrm{hrs}(7 \mathrm{am}-7 \mathrm{pm})$ prior to the start of the experiments. Two types of fabric were used, being either nylon or cotton. Worn socks were inserted in the central black cylinder of the trap (see Fig. 1) and fitted in such way that the airflow was not obstructed. Dry, clean socks were used in the control traps. The weight increase (water/odours) between clean and worn nylon and cotton socks was (average \pm SD of 4 days) $180 \pm 29 \mathrm{mg}$ and $670 \pm 186 \mathrm{mg}$, respectively. Every day a new clean set of socks was used for the experiments (16 nights).

In a second series of experiments nylon socks were worn by both volunteers for a period of 12 hours only. The socks were subsequently used at $24 \mathrm{~h}$ intervals for trapping ( 7 pm -7 am) until catch levels dropped to $<5$ mosquitoes per day for two consecutive days. Socks were not removed from the traps during the day ( $7 \mathrm{am}-7 \mathrm{pm})$ and the outlet of the black pipe (Fig. 1) was covered with aluminium foil. Traps (including the socks) were put in a freezer $\left(-5^{\circ} \mathrm{C}\right)$ for $20-30$ min every morning to kill the mosquitoes caught the previous night.

\section{Other experimental odours}

In a series of five further experiments (replicated over four nights each), traps baited with $\mathrm{NH}_{3}, \mathrm{CO}_{2}$, 1-octen-3-ol, foot odour (collected as described above) were compared against unbaited traps. Ammonia was diluted in distilled water to obtain various concentrations $(0.1,1,10 \%(\mathrm{v} / \mathrm{v})$ or undiluted, offered as $10 \mathrm{ml}$ aliquots) offered from an open glass vial (aperture $1 \mathrm{~cm}$ ) placed near the odour outlet in the central tube of the trap. $\mathrm{CO}_{2}$ was released in the central tube (at $500 \mathrm{ml} / \mathrm{min}$ ) from a pressurised gas cylinder through $5 \mathrm{~mm}$ silicon tubing and controlled using a flow-meter. 1-Octen-3-ol was dispensed $(\sim 0.5 \mathrm{mg} / \mathrm{h})$ from commercially available cartridges (American Biophysics, RI, USA) and placed in the central tube of the trap. A new cartridge was used on each test night.

In order to study the influence of various odours on trap catches, either alone or in combination, four traps were run simultaneously in the four corners of the greenhouse.

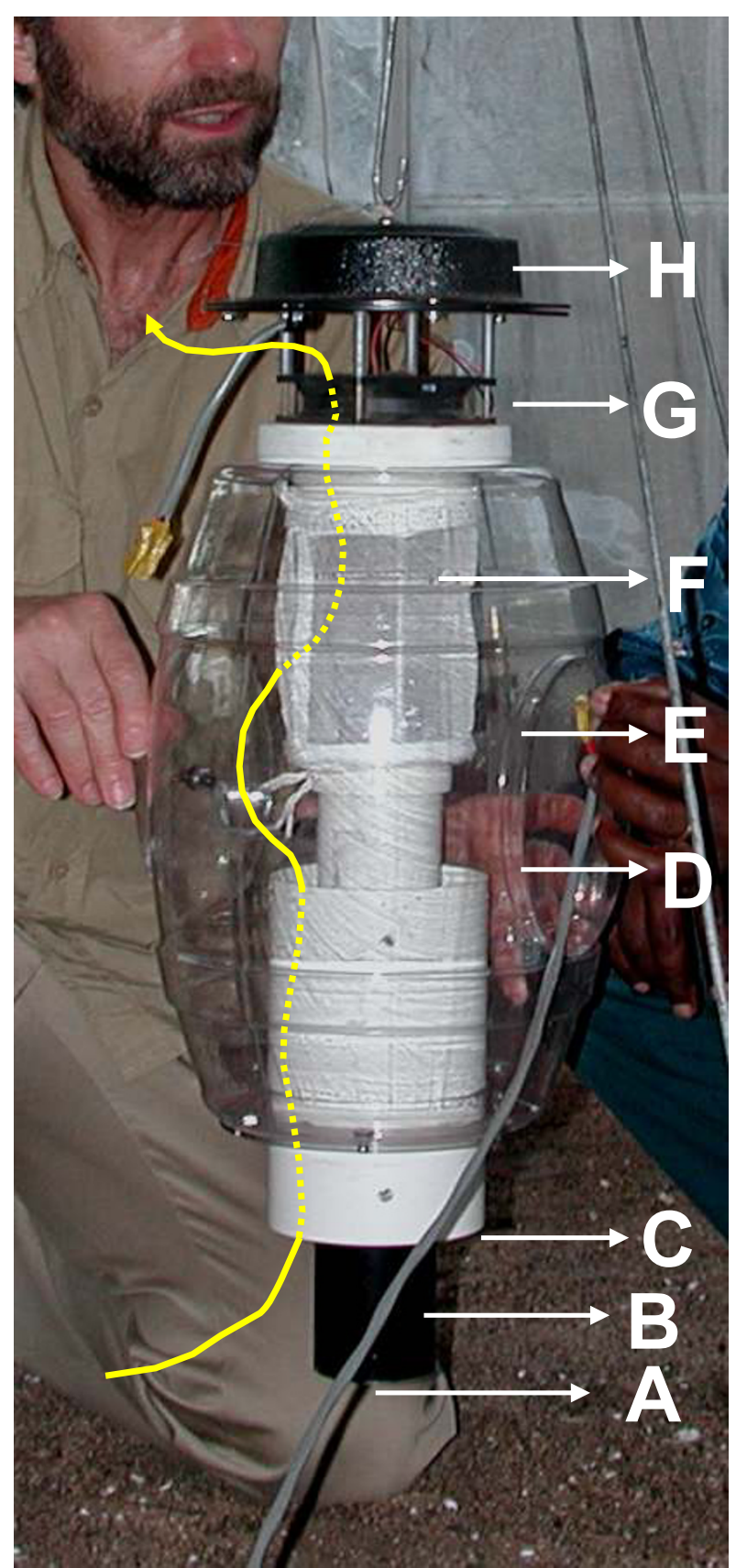

\section{Figure I}

The MMX counterflow geometry trap (American Biophysics, RI, USA). A: Experimental odour outlet; B: Central tube; C: Mosquito entry point; D: Plastic transparent mosquito holding container; F: Computer fan pumping odour downward; G: Computer fan sucking air upward; H: Rain shield. The yellow arrow depicts the flow of air through the trap.

Treatments and traps were randomised over positions to complete one block of a $4 \times 4$ Latin square ( 4 test days). In three test series, foot odour and/or ammonia, carbon 
Table I: MM-X trap catches ( $n=200$ released per night) of An. gambiae s.s. (Njage strain) for 4 trap nights when baited with worn socks of either nylon or cotton fabric worn by BNN or BGJK. Clean socks of the same fabric served as controls.

\begin{tabular}{|c|c|c|c|c|c|}
\hline Person Day & & Nylon & Control & Cotton & Control \\
\hline \multirow[t]{5}{*}{ BNN } & 1 & 53 & 2 & 93 & 2 \\
\hline & 2 & 37 & 4 & 38 & 9 \\
\hline & 3 & 34 & 1 & 41 & 4 \\
\hline & 4 & 55 & 2 & 25 & 2 \\
\hline & \multicolumn{3}{|c|}{$F=|4| .8 ; P<0.00 \mid$} & \multicolumn{2}{|c|}{$F=99.9 ; P<0.001$} \\
\hline \multirow[t]{5}{*}{ BGJK } & I & 75 & 21 & 74 & $I^{*}$ \\
\hline & 2 & 98 & 5 & 58 & 1 \\
\hline & 3 & 95 & 0 & 38 & 2 \\
\hline & 4 & 59 & 2 & 84 & 6 \\
\hline & \multicolumn{3}{|c|}{$\mathrm{F}=12.1 ; \mathrm{ns}$} & \multicolumn{2}{|c|}{$F=76.3 ; P<0.001$} \\
\hline
\end{tabular}

* Catch for the first night excluded (9-0), with cold weather, strong winds and rain.

dioxide and/or ammonia, and foot odour and/or carbon dioxide were tested. Concentrations of volatiles were similar to those described above.

\section{Statistical analysis}

Trap catches were $\log (\mathrm{n}+1)$ transformed and subjected to Latin square analysis of variance [39]. A F-test significant at $\mathrm{P}<0.05$ was followed by a Least Significant Difference (LSD) post hoc test to sort out differences between treatment means.

\section{Results}

When traps were baited with worn socks only, average ( \pm SD) catches over eight test nights were $47 \pm 21$ for BNN and $73 \pm 20$ for BGJK (Table 1). Three out of four completed Latin square blocks yielded highly significant attraction to foot odour and in spite of high catches in the first block of BGJK, the conservative discriminatory levels

Table 2: MM-X trap catches ( $n=200$ released per night) of $A n$. gambiae s.s. (Njage strain) when baited with a nylon (BGJK) or cotton sock (BNN) worn for $12 \mathrm{hr}$ only and then used at $24 \mathrm{hr}$ intervals afterwards. Clean socks of the same fabric served as controls.

\begin{tabular}{lcccc}
\hline Hour* & Nylon & Control & Cotton & Control \\
\hline $0-12$ & $59 \mathrm{~b}$ & 2 & 73 & 2 \\
$24-36$ & 97 & 0 & 31 & 0 \\
$48-60$ & 40 & 2 & 78 & 0 \\
$72-84$ & 59 & 1 & 48 & 0 \\
$96-108$ & 33 & 0 & 5 & 0 \\
$120-132$ & 43 & 0 & 13 & 0 \\
$144-156$ & 55 & 2 & 6 & 1 \\
$168-180$ & 55 & 1 & 7 & 0 \\
$192-204$ & 28 & 1 & 7 & 1 \\
\hline
\end{tabular}

* Starting from the time the socks were removed; **Socks from last day Table I. needed when applying a double replicate of $2 \times 2$ Latin square cross-over designs caused insignificance because of the control trap yielding 21 specimens in the first night. The overall effect of fabric (nylon or cotton) was not significant.

When evaluating the attractiveness of foot odours collected on socks worn for 12 hours only, unexpectedly high levels of residual activity were observed (Table 2). This effect was stronger for BGJK than for BNN. Nevertheless, two days after collection of foot odour of BNN, 39\% (78/ 200 ) of released mosquitoes were caught, whereas BGJK's residual odours still trapped nearly $27.5 \%$ (55/200) of the females released as long as seven days after initial odour collection.

Albeit at lower levels, $\mathrm{NH}_{3}$ when offered in various concentrations, raised trap catches significantly (at $0.1,1$ and $10 \%$; Table 3A) except when offered undiluted. No clear dose-response effect was observed. As expected, $\mathrm{CO}_{2}$, a well-known kairomone, elicited strong behavioural responses, with an average $( \pm$ SD) of $110 \pm 26$ females collected ( $55 \%$ of the number released) per night. In contrast, 1 -octen-3-ol at $0.5 \mathrm{mg} / \mathrm{hr}$ did not raise catches significantly over those collected by the control trap (Table 3C). When foot odour was combined with $\mathrm{NH}_{3}$ $(10 \% \mathrm{v} / \mathrm{v})$ catches remained significantly different from the control trap, though on average similar to catches with foot odour only (Table 3D). However, when $\mathrm{CO}_{2}$ was added to this blend, a sharp and significant increase in catches was observed, with an average $( \pm$ SD) catch of 181 \pm 43 females ( $\sim 91 \%$ of the number released; Table 3E). In fact, it was noticed that, even in the absence of sugar sources in the greenhouse, mosquitoes managed to survive between test periods ( $12 \mathrm{hrs}$ ), as catches in this series twice exceeded the 200 insects released during the experimental night.

When four traps were tested simultaneously, and three of these contained odour baits, trap catches with $\mathrm{NH}_{3}$ were similar to those of the control trap and significantly reduced catches when combined with foot odour over foot odour alone (Table 4A). In a further series (Table 4B), $\mathrm{NH}_{3}$ again did not increase trap catches significantly, nor did it affect catches when combined with carbon dioxide. As observed in previous experiments (Table 3E), a strong increase in catches when foot odours were combined with $\mathrm{CO}_{2}$ was expected. Table $4 \mathrm{C}$ shows not only that foot odour and $\mathrm{CO}_{2}$ alone caused significant increases in catches over control traps, but also that the combination of the two led to a significant and synergistic increase in catch levels (i.e. the combination of the two yielded significantly higher catches than either or the sum of the two baits alone). 
Table 3: MM-X trap catches ( $n=200$ released per night) of $A n$. gambiae s.s. (Mbita strain) for 4 trap nights when baited with (A) $\mathrm{NH}_{3}(0 . \mathrm{I}, \mathrm{I}, \mathrm{I} 0$ or $100 \%)$, (B) $\mathrm{CO}_{2}(500 \mathrm{ml} / \mathrm{min})$, (C) I-octen-3-ol, (D) foot odour (FO; from BNN) $+\mathrm{NH}_{3}(10 \%)$, (E) foot odour (FO; from $\mathrm{BNN})+\mathrm{CO}_{2}(500 \mathrm{ml} / \mathrm{min})+\mathrm{NH}_{3}$. Controls were unbaited traps.

\begin{tabular}{|c|c|c|c|c|c|}
\hline Expt. & Day & $\mathrm{NH}_{3}(0.1 \%)$ & Control & $\mathrm{NH}_{3}(\mathrm{I} .0 \%)$ & Control \\
\hline \multirow[t]{11}{*}{ A } & I & 18 & 1 & 29 & 3 \\
\hline & 2 & 11 & I & 15 & 3 \\
\hline & 3 & 7 & 1 & 17 & 2 \\
\hline & 4 & 5 & 2 & 18 & 1 \\
\hline & \multicolumn{3}{|c|}{$F=19.2 ; P<0.05$} & \multicolumn{2}{|c|}{$F=69.4 ; P<0.001$} \\
\hline & & $\mathrm{NH}_{3}(\mathrm{I} 0 \%)$ & Control & $\mathrm{NH}_{3}(100 \%)$ & Control \\
\hline & 1 & 31 & 2 & 22 & 3 \\
\hline & 2 & 11 & I & 14 & 2 \\
\hline & 3 & 25 & 2 & 11 & 5 \\
\hline & 4 & 16 & 2 & 3 & 2 \\
\hline & \multicolumn{3}{|c|}{$F=1396.8 ; P<0.001$} & \multicolumn{2}{|c|}{$F=6.58 ; n s$} \\
\hline \multirow[t]{6}{*}{$\mathrm{B}, \mathrm{C}$} & & $\mathrm{CO}_{2}$ & Control & I-octen-3-ol & Control \\
\hline & 1 & 122 & 1 & 1 & 1 \\
\hline & 2 & 119 & 1 & 5 & 1 \\
\hline & 3 & 127 & 1 & 2 & 4 \\
\hline & 4 & 71 & 0 & 20 & 5 \\
\hline & \multicolumn{3}{|c|}{$F=7977.3 ; P<0.001$} & \multicolumn{2}{|c|}{$\mathrm{F}=1 \mathrm{I} .9 ; \mathrm{ns}$} \\
\hline \multirow[t]{6}{*}{$D, E$} & & $\mathrm{FO}+\mathrm{NH}_{3}$ & Control & $\mathrm{FO}+\mathrm{NH}_{3}+\mathrm{CO}_{2}$ & Control \\
\hline & I & 120 & 1 & 190 & 5 \\
\hline & 2 & 73 & I & 205 & 2 \\
\hline & 3 & 82 & 0 & 210 & 0 \\
\hline & 4 & 65 & 3 & 118 & 0 \\
\hline & \multicolumn{3}{|c|}{$F=296.6 ; P<0.001$} & \multicolumn{2}{|c|}{$F=81.9 ; P<0.001$} \\
\hline
\end{tabular}

An overview of the experimental baits and catch levels is shown in Figure 2. Overall, catch levels of both strains of An. gambiae s.s. when responding to foot odour, appeared similar.

\section{Discussion}

In the early 1990s, foot odour was first incriminated as influencing the selection of biting sites by An. gambiae s.s. on humans [40]. Subsequently it was found that this mosquito also responds strongly to Limburger cheese volatiles, reminiscent of human foot odour, in laboratory bioassays [26,41,42]. Repeated efforts to show similar effects in the field, when baiting various trap models and electric nets [43] with these complex odours were disappointing [44] and not reported (Knols and Mboera, unpublished data). However, in the present study it was clearly demonstrated that foot odours, when collected on either cotton or nylon sock fabric, can significantly increase trap catches and thus confirm earlier laboratory findings [40]. It is noteworthy that the residual activity of these emanations spanned several days, corroborating earlier studies claiming that previously occupied houses
Table 4: $4 \times 4$ Latin square experiments using various combinations of odours in combination with MM-X traps. Catches of An. gambiae s.s. (Mbita strain) for 4 trap nights (200 released per night), including totals caught are shown. FO = Foot odour (from BNN). Totals in the same column not followed by the same letter are significantly different at $P<0.05$.

\begin{tabular}{|c|c|c|c|c|c|c|c|c|}
\hline Treatment & Day & 1 & 2 & 3 & 4 & Total & $\mathrm{F}$ & $P$ \\
\hline \multicolumn{9}{|l|}{ (A) } \\
\hline Control & & 4 & 2 & 4 & 3 & $13 \mathrm{a}$ & 18.7 & $<0.001$ \\
\hline $\mathrm{FO}$ & & 16 & 69 & 39 & 28 & $152 \mathrm{~b}$ & & \\
\hline $\mathrm{NH}_{3}^{*}$ & & 6 & 8 & 5 & 8 & $27 \mathrm{a}$ & & \\
\hline $\mathrm{FO}+\mathrm{NH}_{3}$ & & 9 & 29 & 7 & 15 & $60 c$ & & \\
\hline \multicolumn{9}{|l|}{ (B) } \\
\hline Control & & 9 & II & 11 & 8 & $39 a$ & 50.1 & $<0.001$ \\
\hline $\mathrm{CO}_{2} * *$ & & 35 & 78 & 51 & 56 & $220 \mathrm{~b}$ & & \\
\hline $\mathrm{NH}_{3} *$ & & 12 & 14 & 6 & 7 & $39 \mathrm{a}$ & & \\
\hline $\mathrm{CO}_{2}+\mathrm{NH}_{3}$ & & 62 & 62 & 34 & 53 & $211 \mathrm{~b}$ & & \\
\hline \multicolumn{9}{|l|}{ (C) } \\
\hline Control & & II & 6 & 8 & 5 & $30 \mathrm{a}$ & 34.9 & $<0.001$ \\
\hline FO & & 14 & 21 & 31 & 27 & $93 \mathrm{~b}$ & & \\
\hline $\mathrm{CO}_{2} * *$ & & 35 & 14 & 31 & 49 & $129 \mathrm{~b}$ & & \\
\hline $\mathrm{FO}+\mathrm{CO}_{2} * *$ & & 77 & 98 & 105 & 71 & $351 \mathrm{c}$ & & \\
\hline
\end{tabular}

or worn clothing attracted mosquitoes several days after having been vacated or worn, respectively [45]. These findings clearly indicate that as yet unknown kairomones with low volatility are present in foot odour. Progression in the identification of active fractions of foot odour is currently underway (A. Hassanali, personal communication).

Ammonia has been demonstrated to elicit behavioural and sensory physiological responses of many haematophagous arthropods including Afrotropical Anopheles [46-48]. Either on its own, but particularly when combined with lactic acid and a blend of carboxylic fatty acids, laboratory assays confirmed the kairomonal effect of this chemical [48]. The current findings show a mildly attractive effect of ammonia alone, but did not indicate an additive or synergistic effect when combined with either foot odour or $\mathrm{CO}_{2}$. It should be noted though that the high volatility of this compound in an aqueous solution could have caused only short-term effects. Alternatively, with ammonia already naturally present in foot odour additional ammonia did not cause any measurable behavioural effect. A slow-release system, analogous to the continuous production of ammonia on the human skin through microbial breakdown of urea and amino acids [46], might improve trap catches.

Carbon dioxide, in all experiments, dramatically increased trap catches. Regretfully, the use of this kairomone either in gaseous form or as dry ice remains a major 


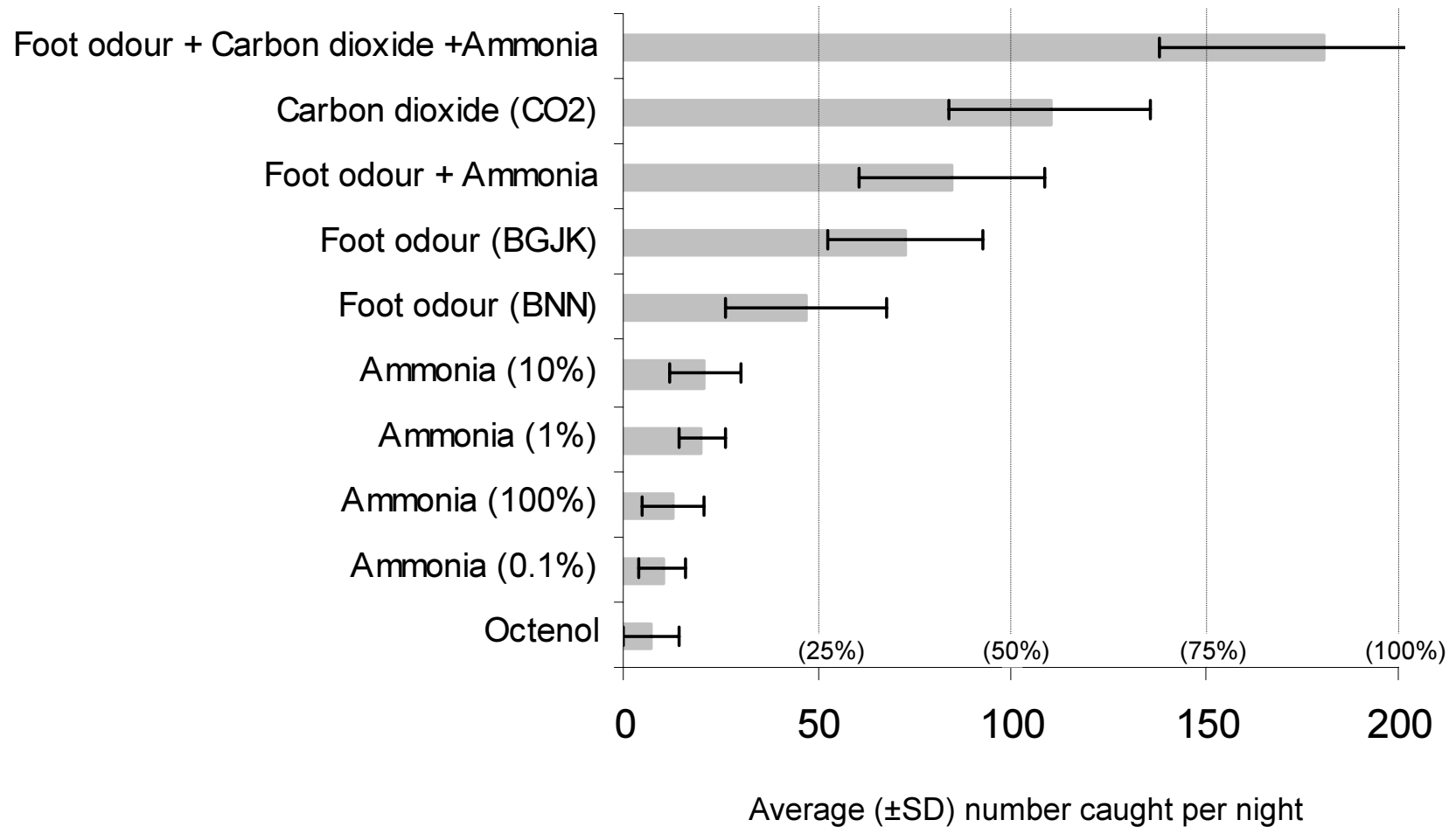

\section{Figure 2}

Average catch levels $( \pm S D)$ for the different odours and combinations tested. Percentages indicate the proportion of overall number of mosquitoes released.

hurdle for its inclusion in trapping devices in the tropics. Although alternative delivery systems have been developed (such as the catalytic combustion of propane), these still depend on costly gas tanks not widely available. Although it has been argued that anthropophilic vectors cannot depend solely on this chemical to locate humans [1], $\mathrm{CO}_{2}$ clearly synergises responses to other human-specific substances. Although mosquito surveillance programmes may use $\mathrm{CO}_{2}$-baited devices, widespread use of traps at household level will ultimately require identification of potent bait without the need for $\mathrm{CO}_{2}$. At present, kairomones present in foot odour seem to offer the best promise for this. It should be noted though, that semifield systems cannot replace field studies and that verification of findings should always take place. Similarly, although this trapping system has proven useful for field sampling of mosquitoes (Yu Tong Qiu et al., unpublished data from field studies in the Gambia), it should be considered primarily as an experimental tool to evaluate can- didate kairomones and not directly as a replacement for existing sampling tools for adult anophelines.

\section{Conclusion}

In spite of decades of research, no effective trapping system for An. gambiae is currently available. Lack of appropriate trapping mechanisms and systems that enable rigorous evaluation have seriously hindered progress. The current work has demonstrated the usefulness of contained semi-field environments to rapidly evaluate the potency of bait systems and confirm laboratory findings. Foot odour was shown for the first time to elicit behavioural responses in this system, and acted synergistically with carbon dioxide. The role of ammonia remains less clear, and merits further evaluation.

\section{Authors' contributions}

BNN and WR conducted the experimental work and drafted the manuscript. BGJK conceived of the studies and 
wrote the final version of the manuscript in collaboration with WT.

\section{Acknowledgements}

We thank Jackton Arija for rearing experimental mosquitoes and technical support. American Biophysics Corporation (Greenwich, RI, USA) generously provided the MM-X traps under their shared data research programme. This research was supported by funds from the National Institutes of Health (NIH; grant \# IUI 9AI455I I) and the Dutch Scientific Organisation (NWO, VIDI grant to BGJK, \# 864.03.004).

\section{References}

I. Takken W, Knols BGJ: Odor-mediated behavior of Afrotropical malaria mosquitoes. Annu Rev Entomol 1999, 44:131-57.

2. Enserink M: What mosquitoes want: Secrets of host attraction. Science 2002, 298:90-92.

3. Sithiprasasna R, Jaichapor B, Chanaimongkol S, Khongtak P, Lealsirivattanakul T, Tiang-Trong S, Burkett DA, Perich MJ, Wirtz RA, Coleman RE: Evaluation of candidate traps as tools for conducting surveillance for Anopheles mosquitoes in a malaria-endemic area in western Thailand. I Med Entomol 2004, 4I:I5I - I57.

4. Vale GA: Development of baits for tsetse flies (Diptera: Glossinidae) in Zimbabwe. J Med Entomol 1993, 30:831-842.

5. Billingsley PF, Charlwood JD, Knols BG]: Rapid assessment of malaria risk using entomological techniques: Taking an Epidemiological Snapshot. In Environmental change and malaria risk Edited by: Takken W, Martens P. Chapter 6, Kluwer Academic Publishers. Frontis series no. 9.51-67.

6. Willemse LP, Takken W: Odor-induced host location in tsetse flies (Diptera: Glossinidae). J Med Entomol 1994, 3 I:775-794.

7. Torr SJ: The tsetse (Diptera: Glossinidae) story: implications for mosquitoes. J Am Mosq Control Assoc 1994, 10:258-265.

8. White GB: Anopheles gambiae complex and disease transmission in Africa. Trans R Soc Trop Med Hyg 1974, 68:278-298.

9. Lines JD, Curtis CF, Wilkes TJ, Njunwa KJ: Monitoring human-biting mosquitoes (Diptera: Culicidae) in Tanzania with light traps hung beside mosquito nets. Bull Entomol Res I99I, 8I:77-84.

10. Costantini C, Gibson G, Brady J, Merzagora L, Coluzzi M: A new odour-baited trap to collect host-seeking mosquitoes. Parassitologia 1993, 35:5-9.

II. Dia I, Diallo D, Duchemin JB, Ba Y, Konate L, Costantini C, Diallo M: Comparisons of human-landing catches and odor-baited entry traps for sampling malaria vectors in Senegal. J Med Entomol 2005, 42:104-109.

12. Mathenge EM, Killeen GF, Oulo DO, Irungu LW, Ndegwa PN, Knols BGJ: Development of an exposure-free bednet trap for sampling Afrotropical malaria vectors. Med Vet Entomol 2002, 16:67-74.

13. Mathenge EM, Omweri GO, Irungu LW, Ndegwa PN, Walczak E, Smith TA, Killeen GF, Knols BG]: Comparative field evaluation of the Mbita trap, Centers for Disease Control light trap and the human landing catch for sampling of malaria vectors in western Kenya. Am J Trop Med Hyg 2004, 70:33-37.

14. Mathenge EM, Misiani GO, Oulo DO, Irungu LW, Ndegwa PN, Smith TA, Killeen GF, Knols BG]: Comparative performance of the Mbita trap, CDC light trap and the human landing catch in the sampling of Anopheles arabiensis, An. funestus and culicine species in a rice irrigation scheme in western Kenya. Malar J 2005, 4:7.

15. Mukabana WR, Takken W, Coe R, Knols BGJ: Host-specific cues cause differential attractiveness of Kenyan men to the African malaria vector Anopheles gambiae. Malar J 2002, I:I7.

16. Kelly DW: Why are some people bitten more than others? Trends Parasitol 2001, 17:578-58I.

17. Mukabana WR, Takken W, Killeen GF, Knols BGJ: Allomonal effect of breath contributes to differential attractiveness of humans to the African malaria vector Anopheles gambiae. Malar J 2004, 3:I.

18. Braks MA, Anderson RA, Knols BG]: Infochemicals in mosquito host selection: human skin microflora and Plasmodium parasites. Parasitol Today 1999, 15:409-4I3.
19. Braks MAH, Takken W: Incubated human sweat but not fresh sweat attracts the malaria mosquito Anopheles gambiae sensu stricto. J Chem Ecol 1999, 25:663-672.

20. Knols BG], Meijerink J: Odors influence mosquito behavior. $\mathrm{Sci}$ Med 1997, 4:56-63.

21. Stoddart DM: The Scented Ape: The biology and culture of human odour Cambridge University Press; 1990.

22. Bernier UR, Kline DL, Barnard DR, Schreck CE, Yost RA: Analysis of human skin emanations by gas chromatography/mass spectrometry. 2. Identification of volatile compounds that are candidate attractants for the yellow fever mosquito (Aedes aegypti). Anal Chem 2000, 72:747-756.

23. Gillies MT: The role of carbon dioxide in host finding by mosquitoes. Bull Ent Res 1980, 70:525-532.

24. Costantini C, Gibson G, Sagnon N, Della Torre A, Brady J, Coluzzi M: Mosquito responses to carbon dioxide in a west African Sudan savanna village. Med Vet Entomol 1996, 10:220-227.

25. Mboera LEG, Knols BG], Braks MAH, Takken W: Comparison of carbon dioxide-baited trapping systems for sampling outdoor mosquito populations in Tanzania. Med Vet Entomol 2000, I 4:257-263.

26. Knols BGJ, Van Loon JJA, Cork A, Robinson RD, Adam W, Meijerink J, De Jong R, Takken W: Behavioural and electrophysiological responses of the female malaria mosquito Anopheles gambiae s.s. Giles (Diptera: Culicidae) towards Limburger cheese volatiles. Bull Entomol Res 1997, 87:15I-159.

27. Costantini C, Birkett MA, Gibson G, Ziesmann J, Sagnon NF, Mohammed HA, Coluzzi M, Pickett JA: Electroantennogram and behavioural responses of the malaria vector Anopheles gambiae to human-specific sweat components. Med Vet Entomol 200I, I5:259-266.

28. Healy TP, Copland MJ: Human sweat and 2-oxopentanoic acid elicit a landing response from Anopheles gambiae. Med Vet Entomol 2000, I 4:195-200.

29. Takken W, Dekker T, Wijnholds YG: Odor-mediated behavior of Anopheles gambiae s.s. Giles and An. stephensi Liston in response to $\mathrm{CO}_{2}$, acetone and I-octen-3-ol. J Insect Behav 1997, 10:395-407.

30. Hallem EA, Nicole Fox A, Zwiebel LJ, Carlson JR: Olfaction: mosquito receptor for human-sweat odorant. Nature 2004, 427:212-213.

3I. Braks MAH, Meijerink J, Takken W: The response of the malaria mosquito, Anopheles gambiae, to two components of human sweat, ammonia and L-lactic acid, in an olfactometer. Physiol Entomol 2001, 26:142-148.

32. Meijerink J, Braks MA, Van Loon JJ: Olfactory receptors on the antennae of the malaria mosquito Anopheles gambiae are sensitive to ammonia and other sweat-borne components. J Insect Physiol 200I, 47:455-464.

33. Mboera LEG, Takken W, Sambu EZ: The response of Culex quinquefasciatus (Diptera: Culicidae) to traps baited with carbon dioxide, I-octen-3-ol, acetone, butyric acid and human foot odour in Tanzania. Bull Ent Res 2000, 90:155-159.

34. Mboera LEG, Knols BG], Braks MAH, Takken W: Comparison of carbon dioxide-baited trapping systems for sampling outdoor mosquito populations in Tanzania. Med Vet Ent 2000, I4:257-263.

35. Mboera LEG, Takken W, Mdira KY, Pickett JA: Sampling gravid Culex quinquefasciatus (Diptera: Culicidae) in Tanzania with traps baited with synthetic oviposition pheromone and grass infusions. J Med Ent 2000, 37:172-176.

36. Sudia WD, Chamberlain RW: Battery-operated light trap: An improved model. Mosq News 1968, 22:126-129.

37. Knols BG], Njiru BN, Mathenge EM, Mukabana WR, Beier JC, Killeen GF: MalariaSphere: A greenhouse-enclosed simulation of a natural Anopheles gambiae (Diptera:Culicidae) ecosystem in western Kenya. Malar 」 2002, I:13.

38. Kline DL: Comparison of two American Biophysics mosquito traps: the professional and a new counterflow geometry trap. J Am Mosq Control Assoc 1999, I5:276-282.

39. Snedecor GW, Cochran WG: Statistical Methods, Eighth Edition lowa State University Press; 1989.

40. De Jong R, Knols BGJ: Selection of biting sites on man by two malaria mosquito species. Experientia 1995, 51 1:80-84. 
4I. De Jong R, Knols BGJ: Olfactory responses of host-seeking Anopheles gambiae s.s. Giles (Diptera: Culicidae). Acta Trop 1995, 59:333-335.

42. Knols BGJ, De Jong R: Limburger cheese as an attractant for the malaria mosquito Anopheles gambiae s.s. Parasitol Today 1996, I2:159-161.

43. Knols BG], Mboera LEG, Takken W: Electric nets for studying odour-mediated host-seeking behaviour of mosquitoes. Med Vet Entomol 1998, I 2: I I6-I 20.

44. Murphy MW, Dunton RF, Perich MJ, Rowley WA: Attraction of Anopheles (Diptera: Culicidae) to volatile chemicals in Western Kenya. I Med Entomol 200I, 38:242-244.

45. Haddow AJ: The mosquito fauna and climate of native huts at Kisumu, Kenya. Bull Entomol Res 1942, 33:91-142.

46. Braks MAH, Meijerink J, Takken W: The response of the malaria mosquito, Anopheles gambiae, to two components of human sweat, ammonia and L-lactic acid, in an olfactometer. Physiol Entomol 200I, 26: I 42-I48.

47. Meijerink J, Braks MAH, Van Loon JJ: Olfactory receptors on the antennae of the malaria mosquito Anopheles gambiae are sensitive to ammonia and other sweat-borne components. J Insect Physiol 200I, 47:455-464.

48. Smallegange RC, Qiu YT, van Loon J], Takken W: Synergism between ammonia, lactic acid and carboxylic acids as kairomones in the host-seeking behaviour of the malaria mosquito Anopheles gambiae sensu stricto (Diptera: Culicidae). Chem Senses 2005, 30:145-152.

Publish with Bio Med Central and every scientist can read your work free of charge

"BioMed Central will be the most significant development for disseminating the results of biomedical research in our lifetime. "

Sir Paul Nurse, Cancer Research UK

Your research papers will be:

- available free of charge to the entire biomedical community

- peer reviewed and published immediately upon acceptance

- cited in PubMed and archived on PubMed Central

- yours - you keep the copyright

Submit your manuscript here:

http://www.biomedcentral.com/info/publishing_adv.asp
BiolMedcentral 